\title{
Diverse Roles of TRPV4 in Macrophages: A Need for Unbiased Profiling
}

\author{
Thanh-Nhan Nguyen ${ }^{1,2}$, Ghizal Siddiqui ${ }^{3}$, Nicholas A. Veldhuis ${ }^{1,2 *}$ and Daniel P. Poole ${ }^{1,2 *}$ \\ ${ }^{1}$ Drug Discovery Biology Theme, Monash Institute of Pharmaceutical Sciences, Monash University, Parkville, VIC, Australia, \\ 2 Australian Research Council (ARC) Centre of Excellence in Convergent Bio-Nano Science \& Technology, Monash University, \\ Parkville, VIC, Australia, ${ }^{3}$ Drug Delivery, Disposition and Dynamics Theme, Monash Institute of Pharmaceutical Sciences, \\ Monash University, Parkville, VIC, Australia
}

Transient receptor potential vanilloid 4 (TRPV4) is a non-selective mechanosensitive ion channel expressed by various macrophage populations. Recent reports have characterized the role of TRPV4 in shaping the activity and phenotype of macrophages to influence the innate immune response to pathogen exposure and inflammation. TRPV4 has been studied extensively in the context of inflammation and inflammatory pain. Although TRPV4 activity has been generally described as pro-inflammatory, emerging evidence suggests a more complex role where this channel may also contribute to antiinflammatory activities. However, detailed understanding of how TRPV4 may influence the initiation, maintenance, and resolution of inflammatory disease remains limited. This review highlights recent insights into the cellular processes through which TRPV4 contributes to pathological conditions and immune processes, with a focus on macrophage biology. The potential use of high-throughput and omics methods as an unbiased approach for studying the functional outcomes of TRPV4 activation is also discussed.

Keywords: TRP channels, mechanosensation, macrophage, inflammation, transient receptor potential vanilloid 4 (TRPV4)

\section{INTRODUCTION}

Inflammation is an essential defense mechanism generated by the immune system to protect the body from harmful stimuli or pathogen infection (1). Normally, inflammation is actively resolved to prevent tissue damage. This tightly regulated process involves the spatially and temporally controlled production of mediators leading to dilution of chemokine gradients to ensure that inflammatory responses subside in a timely fashion. Processes which resolve inflammation and rectify tissue homeostasis include reduction or cessation of tissue infiltration by neutrophils, apoptosis of spent neutrophils, down-regulation of chemokines and cytokines, macrophage transformation, and the initiation of healing $(2,3)$. Disruption of the control mechanisms that underlie these processes results in prolonged or uncontrolled inflammation, which is associated with chronic disease including inflammatory arthritis (4), inflammatory bowel disease (5), pulmonary diseases (6), atherosclerosis (7), foreign body response (8) and fibrosis (9).

The transient receptor potential (TRP) superfamily of ion channels plays important and emerging roles in inflammatory and immune-mediated diseases (10). One of the best 
characterized members is transient receptor potential vanilloid 4 (TRPV4), which is expressed by immune cells including macrophages (11-14), neutrophils (15), and dendritic cells. TRPV4 is a tetrameric ion channel with each subunit containing 6 transmembrane domains, a pore-forming loop, and 6 highly conserved ankyrin repeat domains in the cytoplasmic N-terminus (16). The functional role of TRPV4 and involvement in pathophysiology is most extensively defined for macrophages $(12,13,17,18)$. TRPV4 is expressed by various macrophage populations including tissue-resident macrophages located in the lung, gut, brain, liver, and skin (11-14, 19-21). Although TRPV4 has long been associated with proinflammatory roles, recent studies propose that TRPV4 activity can also influence macrophage function to promote the reduction or resolution of inflammatory damage $(12,13,22)$. This raises a key question: how can a single ion channel regulate two opposing processes? In this review, we first highlight emerging evidence for the involvement of TRPV4 as a mechanosensitive channel in pathological conditions and immune responses, with a specific focus on macrophages. We then explore how the use of high-throughput omics approaches could reveal greater insight into the complex network of cellular pathways associated with TRPV4 activation.

\section{TRPV4: A POLYMODAL ION CHANNEL AND KEY EFFECTOR OF RECEPTOR SIGNALING}

TRPV4 was first identified as an osmosensitive channel due to its activation by hypotonicity $(23,24)$. It has since been shown to function as a polymodal non-selective cation channel that can be activated by a diverse array of stimuli including mechanical stress (25-28), warm temperature (above $\left.27^{\circ} \mathrm{C}\right)(29,30)$, endogenous polyunsaturated fatty acids (PUFAs) (31-33) and receptoroperated signaling (34). TRPV4 integrates cellular responses to these various stimuli, enabling this channel to influence a broad range of signaling and associated transcriptional events (11-14, 35-52), as summarized in Figure 1, and previously reviewed in detail (53).

TRPV4 is activated by hypoosmolarity, shear stress or direct deflection at cell-substrate contact points. Activation of TRPV4 by cellular indentation or membrane stretch is also commonly reported $(25,54)$, although the relative importance and generality of this mode of gating has recently been questioned based on electrophysiological studies $(27,28)$. This suggests that TRPV4 may only respond directly to specific mechanical cues. It is also evident that TRPV4 activation by hypotonic conditions and shear stress can indirectly modulate channel gating via production of lipid metabolites such as arachidonic acid and its metabolite $5^{\prime}, 6^{\prime}$-EET. This process requires PLA2 and cytochrome $\mathrm{P} 450$ epoxygenase activity $(33,55)$, suggesting that there are parallels between TRPV4 mechanosensitivity and its function as a receptor-operated channel. For example, $G$ proteincoupled receptors (GPCRs) can also promote PLA2 and P450 activity to increase production of the same anandamide and arachidonic acid-derived lipid species. GPCRs, including members of the protease-activated, muscarinic, serotonin, and histamine receptor families, converge on TRPV4 through lipid signaling pathways, presumably as a mechanism to amplify specific signaling and transcriptional events (34). GPCR signaling can also sensitize and enhance the responsiveness of TRPV4 to these lipid metabolites by promoting direct phosphorylation of residues in its cytoplasmic N- and Cterminal domains by PKA, PKC and Src family tyrosine kinases (34). TRPV4 is proposed to be a key effector and 'amplifier' of sensory afferent nerve signaling. GPCR- and protein kinase-dependent sensitization of TRPV4 is associated with increased pain transmission and the peripheral release of neuropeptides and other mediators that promote neurogenic inflammation (56).

Recent studies have extended our understanding of how TRPV4 functions as an effector for receptor signaling and a broader integrator of mechanical cues in different cell types. Integrins are ubiquitously expressed transmembrane mechanoreceptors that are responsible for cell-cell interactions and cell adhesion (57). In endothelial cells, mechanical strain activates TRPV4-mediated $\mathrm{Ca}^{2+}$ influx via the $\beta 1$ integrinCD98hc axis, which is hypothesized to occur through a direct, physical interaction $(58,59)$. In this model, mechanical strain is sensed by $\beta 1$ integrin, which initiates ultra-rapid signal transduction. The signal is transmitted from the cytoplasmic C terminus of $\beta 1$ integrin to the $\mathrm{N}$-terminal cytoplasmic ankyrin domain of TRPV4 via the transmembrane glycoprotein CD98hc, resulting in increased channel gating (59) (Figure 1).

Swain et al. have also recently demonstrated that TRPV4 is an effector protein for other ion channels $(60,61)$. Shear stress and mechanical pushing of pancreatic acinar cells indirectly activated TRPV4 via the fast-inactivating mechanosensitive ion channel Piezo1 (61). Piezol activation initiated a transient $\mathrm{Ca}^{2+}$ influx followed by a sustained elevation of intracellular $\mathrm{Ca}^{2+}$, an effect that was inhibited by the TRPV4 antagonist HC-067047 and mediated by PLA2 $(60,61)$.

The precise mechanisms involved in the TRPV4-dependent inflammatory response are not fully understood. However, it is speculated that changes to the extracellular matrix stiffness during inflammation can activate TRPV4. Scheraga et al. reported that TRPV4 is required for expression of dualspecificity phosphatase 1 (DUSP1) in response to LPS under pathophysiological matrix stiffness $(>8 \mathrm{kPa})$, but not under subthreshold matrix stiffness $(1 \mathrm{kPa})(12)$. DUSP1 is an inflammatory regulator, which inhibits $\mathrm{c}$-Jun $\mathrm{N}$-terminal kinases (JNK) and promotes p38 mitogen-activated protein kinases (MAPK) (12). In addition, calcium influx via TRPV4 also activates calcineurin which promotes nuclear factor of activated T-cells (NFAT) and nuclear factor kappa B (NF-kB) expression $(62,63)$. These studies illustrate an important role for TRPV4 in LPS-induced macrophage activation. Further detail outlining the involvement of TRPV4 in phenotypic switch by macrophages is provided in subsequent sections.

These established and emerging roles of TRPV4 as a key integrator and amplifier of mechano- and receptor-mediated signaling have been demonstrated for a range of distinct cell types including sensory neurons and endothelial cells. This is 


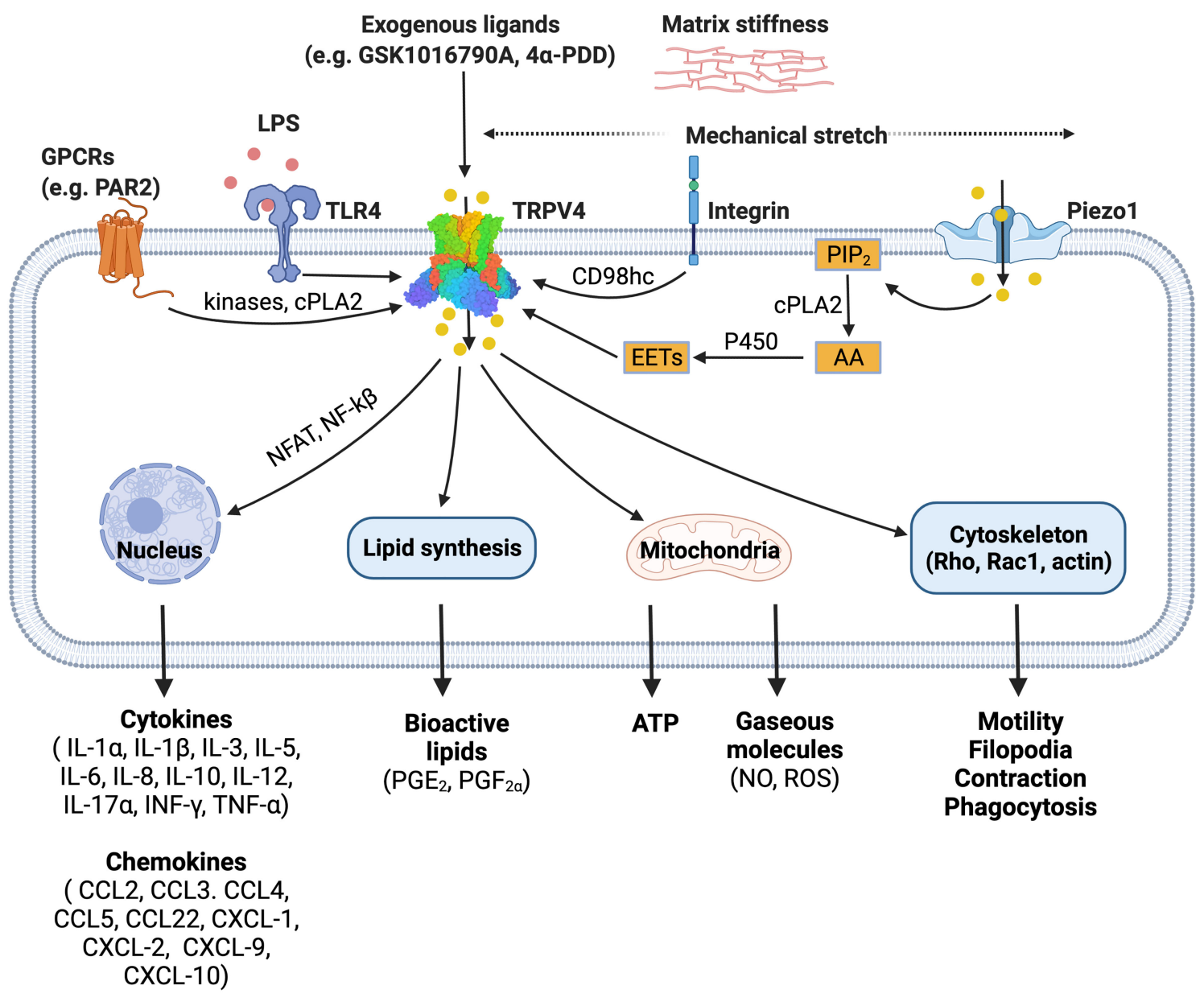

FIGURE 1 | TRPV4 is a polymodal ion channel which can be activated directly or indirectly by a diverse range of stimuli including mechanical force, endogenous mediators, and pharmacological tools. TRPV4 signals through multiple pathways leading to a range of downstream effects on cellular function. The figure illustrates published activation pathways and associated outcomes. TRPV4, transient receptor potential vanilloid 4; GPCRs, G protein-coupled receptors; TLR4, toll-like receptor 4; LPS, lipopolysaccharide; PIP, phosphatidylinositol biphosphate; AA, arachidonic acid; cPLA2, cytosolic phospholipase $A_{2}$; P450, cytochrome P450 epoxygenase; EETs, epoxyeicosatrienoic acids; NFAT, nuclear factor of activated T-cells; NF-kB, nuclear factor kappa B. Figure created with BioRender.com.

consistent with the generality of this function and highlights the associated challenges and opportunities when considering TRPV4 signaling and function as a potential therapeutic target.

\section{TRPV4-EXPRESSING MACROPHAGES AS A THERAPEUTIC TARGET FOR RESOLVING INFLAMMATION}

TRPV4 mRNA or protein has been detected in most organs and tissues $(23,24,30,31,64-70)$ and is expressed by a broad range of cell types including neurons, urothelia, epithelia, immune cells, endothelial cells and aortic and airway smooth muscle $(35,65,68$, 71-73). This widespread expression pattern, coupled with multiple activating modalities, underlies the diverse roles of TRPV4 in physiological processes including volume- and osmo-sensing, thermoregulation, mechanosensation in the vasculature and urinary tract, cell barrier function, bone formation, metabolic disorders, pain, neurogenic inflammation, and gut motility (23, 29, 34, 53, 74-77). TRPV4 also performs critical pro-fibrotic roles and can detect and influence changes to the extracellular matrix (78). TRPV4 antagonists have been pursued and patented for several therapeutic applications including treatment or prevention of lung injury, heart failure, ischemic heart disease, and pain (79). Furthermore, pre-clinical and clinical studies have investigated TRPV4 inhibition as a therapeutic approach for treatment of osteoarthritis (80, 81), atherosclerosis (82), and cancer (83-85). More recently, the use of TRPV4 antagonists for managing comorbidities associated with SARS-CoV-2 infection such as lung edema has also been proposed (86). Despite these extensive efforts to define the importance of TRPV4 in cardiovascular, pulmonary, and inflammatory diseases, there is currently only one drug candidate (GSK2798745) approved for phase II clinical trials $(87,88)$. This clinical candidate is a small molecule, orally available inhibitor with low nanomolar potency (87).The apparent 
lack of therapeutic advancement may reflect limitations to our mechanistic understanding of the precise involvement of TRPV4 in inflammatory and protective processes.

In chronic disease, such as arthritis and joint pain, there are persistent changes to lipid production, osmolarity, increased presence of GPCR ligands (e.g., immune-derived peptides and proteases) and exposure to mechanical cues such as those associated with fibrosis. All these factors have the potential to promote sustained inflammatory signaling, edema, sprouting of nerve fibers, and angiogenesis, and most importantly, influence TRPV4 function (89). Studies using pharmacological tools and $\operatorname{trp} v 4^{-/-}$mice have consistently shown that inhibition or loss of TRPV4 function reduces inflammatory processes and tissue edema. Accordingly, TRPV4 is often described as a pro-inflammatory mediator and a therapeutic target for treating inflammatory disease. However, most of these studies are acute in nature, and may not always adequately reflect proposed resolving roles for TRPV4. Macrophages are of particular interest for targeting inflammation and associated diseases. These cells orchestrate both inflammation and resolution, as summarized in Table 1, and recent evidence supports the dichotomous nature of

TABLE 1 | Summary of factors that are secreted in response to mechanical or pharmacological activation of TRPV4.

\begin{tabular}{|c|c|c|c|c|}
\hline Secreted factors & Experimental conditions & Study models & $\begin{array}{l}\text { Related conditions or } \\
\text { physiological functions }\end{array}$ & Ref. \\
\hline$\uparrow \mathrm{IL}-1 \alpha, \mathrm{IL}-1 \beta, \mathrm{IL}-6, \mathrm{IL}-8$ \& CCL2 & Stretch (cyclic 30\%, $1.25 \mathrm{~Hz}$ ) & $\begin{array}{l}\text { M1 (GM-CSF induced) - } \\
\text { hMDM }\end{array}$ & Lung injury & $(44)$ \\
\hline$\uparrow \mathrm{TNF}-\alpha \& \mathrm{CCL} 2$ & Stretch (cyclic 30\%, $1.25 \mathrm{~Hz}$ ) & $\begin{array}{l}\text { M2 (M-CSF induced) - } \\
\text { hMDM }\end{array}$ & Lung injury & $(44)$ \\
\hline$\uparrow \mathrm{IL}-1 \alpha, \mathrm{IL}-6, \mathrm{IL}-8$ \& CCL22 & $\begin{array}{l}\text { GSK101 (3 nM) or Stretch (cyclic 30\%, } \\
1.25 \mathrm{~Hz} \text { ) }\end{array}$ & $\mathrm{NCl}-\mathrm{H} 292$ & Lung injury & $(44)$ \\
\hline$\uparrow I L-6 \&$ CXCL1 & Mechanical ventilation (30 ml/kg TV) & $\begin{array}{l}\text { Balb/c mice } \\
\text { (bronchoalveolar lavage } \\
\text { fluid) }\end{array}$ & Lung injury & $(44)$ \\
\hline$\downarrow$ IL-6, TNF- $\alpha \&$ ROS & LPS (100 ng/mL) & TRPV4 siRNA RAW267.4 & Lung injury & (62) \\
\hline$\uparrow N O \&$ ROS & $4 \alpha-P D D(10 \mu M)$ & $\mathrm{mAM}$ & Lung injury & (11) \\
\hline$\uparrow \operatorname{ROS}$ & $4 \alpha-P D D(10 \mu \mathrm{M})$ & Endothelial cells & Lung injury & (36) \\
\hline$\uparrow$ IL-6, CXCL1 \& CXCL2 & $\begin{array}{l}\text { LPS }(100 \mathrm{ng} / \mathrm{mL}) \\
\text { clinical strain of Pseudomonas } \\
\text { aeruginosa embedded in agarose beads }\end{array}$ & $\begin{array}{l}\text { trpv4 } 4^{-/} \text {mBMDM } \\
\text { trpv4 }{ }^{-/-} \text {C57BL6 mice } \\
\text { (whole lung lavage fluid) }\end{array}$ & $\begin{array}{l}\text { Pulmonary infection and } \\
\text { injury in murine pneumonia } \\
\text { model }\end{array}$ & $(12)$ \\
\hline$\uparrow I L-1 \beta \downarrow \| L-10$ & $\begin{array}{l}\text { LPS }(100 \mathrm{ng} / \mathrm{mL}) \text { \& pathological matrix } \\
\text { stiffness }(25 \mathrm{kPa})\end{array}$ & $\operatorname{trpv4^{-/}} \mathrm{mBMDM}$ & $\begin{array}{l}\text { Pulmonary infection, injury, } \\
\text { and fibrosis }\end{array}$ & $(13)$ \\
\hline $\begin{array}{l}\downarrow I \mathrm{~L}-1 \alpha, \mathrm{IL}-1 \beta, \mathrm{IL}-3, \mathrm{IL}-5, \mathrm{IL}-6, \mathrm{IL}-12 \mathrm{p} 40, \mathrm{IL}-12 \mathrm{p} 70, \mathrm{IL}-13 \text {, } \\
\mathrm{IL}-17 \alpha, \mathrm{INF}-\gamma, \mathrm{TNF}-\alpha, \mathrm{CCL} 2, \mathrm{CCL} 3, \mathrm{CCL} 4, \mathrm{CCL} 5 \text { \& GM- } \\
\text { CSF }\end{array}$ & LPS $(50$ mg/kg) + GSK219 (1 mg/kg) & $\begin{array}{l}\text { C57BL6/J mice (blood } \\
\text { concentration) }\end{array}$ & Sepsis & $(45)$ \\
\hline$\uparrow$ IL-6, CCL2, CCL5 \& CXCL1 & $\begin{array}{l}\text { Intracolonic administration of } 4 \alpha-\text { PDD } \\
(200 \mu \mathrm{g} \text { in } 40 \% \text { ethanol) }\end{array}$ & Mouse colonic tissue & Colitis & (35) \\
\hline$\uparrow$ IL-8, CCL2, CXCL9 \& CXCL10 & $4 \alpha-P D D(100 \mu M)$ & Caco-2 & Colitis & (35) \\
\hline$\uparrow$ IL-8, CCL5 CXCL9 \& CXCL10 & $4 \alpha-P D D(100 \mu M)$ & T84 & Colitis & (35) \\
\hline$\uparrow \mathrm{CCL} 2$ & $\begin{array}{l}\text { GSK101 (10nM) or Hypotonic stimuli } \\
(200 \mathrm{mOsm} / \mathrm{kg})\end{array}$ & Muller glia & Acute retinal detachment & (46) \\
\hline$\uparrow$ Prostaglandin $F_{2 \alpha}$ & GSK101 (100 nM) & $\begin{array}{l}\text { Aorta from high-salt diet- } \\
\text { fed mouse }\end{array}$ & Hypertension & (43) \\
\hline$\uparrow$ Prostaglandin E2 & GSK101 (300 nM) & $\mathrm{mMM}$ & GI motility & (14) \\
\hline \multirow[t]{8}{*}{$\uparrow$ ATP } & GSK101 (100 nM) or Heat $\left(25-35.8^{\circ} \mathrm{C}\right)$ & $\begin{array}{l}\text { Mouse esophageal } \\
\text { keratinocytes }\end{array}$ & GERD, wound healing & $\begin{array}{l}(37, \\
47)\end{array}$ \\
\hline & $\begin{array}{l}\text { GSK101 (100 nM) or 5,6-EET (500 nM) } \\
\text { or mechanical stretch (120\% lateral } \\
\text { stretch) }\end{array}$ & RGE1-01 & Gastric emptying & $(48)$ \\
\hline & GSK101 (0.01 mL, 50 nM) & $\begin{array}{l}\text { Rat corneal epithelium + } \\
\text { stroma, endothelium, } \\
\text { cornea }\end{array}$ & Acute ocular hypertension & (49) \\
\hline & GSK101 (10 nM - $10 \mu \mathrm{M})$ & $\begin{array}{l}\text { Human bronchial epithelial } \\
\text { cells }\end{array}$ & $\begin{array}{l}\text { COPD (cigarette smoking- } \\
\text { related) }\end{array}$ & (38) \\
\hline & $4 \alpha-\operatorname{PDD}(3 \mu \mathrm{M}, 10 \mu \mathrm{M})$ & HET-1A & Esophagitis and GERD & (39) \\
\hline & GSK101 (100 nM) & Mouse cholangiocytes & Cholestatic liver disorders & (40) \\
\hline & Stretch $(400 \mu \mathrm{m} / \mathrm{s})$ or $4 \alpha-\mathrm{PDD}(10 \mu \mathrm{M})$ & Mouse urothelial cells & Bladder function & (41) \\
\hline & $4 \alpha-P D D(10 \mu M)$ & Astrocyte & $\mathrm{N} / \mathrm{A}$ & (42) \\
\hline
\end{tabular}

mBMDM, mouse bone marrow-derived macrophages; hMDM, human blood monocyte-derived macrophages; mAM, mouse alveolar macrophages; mMM, mouse muscularis macrophages; Gl, gastrointestinal; GERD, gastroesophageal reflux disease; COPD, chronic obstructive pulmonary disease; GSK101, GSK1016790A; GSK219, GSK2193874; 40PDD, $4 \alpha$-Phorbol 12,13-didecanoate; N/A, not available.

$\uparrow=$ increased; $\downarrow=$ decreased. 
TRPV4 in both homeostatic or protective roles and in pathophysiological pathways $(12,13)$. This includes roles in phagocytosis and cytokine production, both of which can be influenced by changes to the cellular environment in which the macrophages are located $(11-13,62)$.

\section{TRPV4 ACTIVITY INFLUENCES MACROPHAGE POLARIZATION AND METABOLISM}

\section{i) TRPV4 and Macrophage Polarization}

Macrophages are a heterogeneous population of cells with the capability to change phenotype and perform specific roles in response to their microenvironment. For many years, the two main extremes of macrophage phenotype were widely accepted as M1 (so-called 'classical' pro-inflammatory phenotype) and M2 ('non-classical' anti-inflammatory phenotype). In reality, macrophages are highly versatile and the distinction between subsets is less clear. Metabolic reprogramming of macrophages is essential for phenotypic switch and immune responses. The M1 and M2 phenotypes have unique metabolic hallmarks (90-92). The manipulation of metabolic pathways in macrophages can alter their functions (93) and targeting of immunometabolism is a promising approach for blocking inflammatory signaling. For example, some anti-inflammatory drugs (e.g., dimethyl fumarate, metformin, methotrexate, and rapamycin) limit inflammation through targeting metabolic events in immune cells including macrophages (90).

TRPV4 activation is associated with phenotypic switch by macrophages $(12,13,17,51,94)$. Current understanding of macrophage polarization is based largely on the use of biochemical cues such as cytokines or LPS to alter cellular phenotype. However, it is important to consider other biophysical factors originating from the microenvironment that may influence phenotype, such as exposure to shear stress and alterations in extracellular matrix stiffness. Several studies have explored how physical stimuli can affect macrophage phenotype, including the involvement of TRPV4 (see Table 1). Moderate cyclic stretch $(7 \%, 0.8 \mathrm{~Hz})$ applied to human peripheral blood mononuclear cells over a 7 -day period increased the relative proportion of M2 cells $\left(\mathrm{CD} 206^{+}\right)$, whereas higher stretch $(12 \%, 0.8 \mathrm{~Hz})$ increased the M1-like $\left(\mathrm{CCR} 7^{+}\right)$phenotype (95). In addition, cyclic or static stretch also triggered production of cytokines, chemokines, and enzymes by macrophages. This included expression of mRNA for iNOS, IL-6, MCP-1, and IL-10 (95, 96). Changes in stiffness of the surrounding extracellular matrix can affect surface protein expression and the secretion profile of macrophages. Previtera et al. (97) cultured murine BMDMs on $0.3-230 \mathrm{kPa}$ polyacrylamide hydrogels and observed that macrophages grown on high stiffness substrates produced elevated levels of pro-inflammatory mediators relative to macrophages grown on softer substrates (97). However, a different study led by Chen et al. (98) showed that murine BMDMs cultured in polyacrylamide hydrogels at a low matrix stiffness $(2.55 \pm 0.32$
$\mathrm{kPa}$ ) displayed an M1-like phenotype, with enhanced CD86 cell surface expression and higher production of ROS, IL-1 $\beta$ and TNF- $\alpha$. In contrast, a higher matrix stiffness $(34.88 \pm 4.22 \mathrm{kPa})$ drove the cells toward an M2-like phenotype with higher CD206 expression, and production of IL-4 and TGF- $\beta$ (98). Direct comparison of these studies is complicated by the differences in the experimental design. In addition, although both used polyacrylamide hydrogels, Previtera et al. (97) pre-treated the gel with laminin (97), which has been shown to promote expression of pro-inflammatory factors in microglia (99) and reduce IL-10 secretion by THP-1 cells (100). However, these studies suggest that mechanosensitive receptors, such as TRPV4 (17), play a critical role in macrophage phenotypic switch in response to the biophysical properties of their environment. This is consistent with other non-TRPV4-related studies demonstrating that matrix stiffness has a profound influence on macrophage polarization states $(100,101)$ and warrants further investigation, as discussed by other manuscripts within this special issue.

\section{ii) TRPV4 and Macrophage Metabolism}

Beyond expression of specific markers, macrophage phenotypes can also be differentiated based on their metabolic profiles, especially those associated with central carbon metabolism. Pro-inflammatory macrophages utilize glycolysis and the pentose phosphate pathway (PPP) to generate sufficient energy to meet higher ATP requirements. Fatty acid synthesis is increased, as this is required both as an energy production pathway and for synthesis of pro-inflammatory lipids, such as prostaglandins. At the same time, oxygen consumption is reduced, and the tricarboxylic acid (TCA) cycle and oxidative phosphorylation (OXPHOS) are suppressed. In contrast, macrophages with a protective phenotype have a normal TCA cycle and higher fatty acid oxidation rate (93).

Greater understanding of how TRPV4 influences macrophage phenotype at the metabolic level will provide further insight into the role of this channel in inflammation and inflammatory diseases. Although this has not been defined in detail, there is some evidence to suggest that TRPV4 can regulate central carbon metabolism, cellular respiration, and lipid metabolism. Several studies report that TRPV4 activation can increase production of reactive oxygen species (ROS) and nitric oxide (NO) $(11,36,102)$ and evoke ATP release (37-42). In macrophages, ROS is largely generated through the NADPH oxidase pathway, while $\mathrm{NO}$ is mainly produced from arginine via the iNOS pathway. Both require $\mathrm{NADPH}$ as a co-factor. The high glycolytic flux of activated macrophages provides glucose-6-phosphate for the PPP, which is the main source of NADPH (93). Furthermore, the TRPV4 activator $4 \alpha-P D D$ reduces mitochondrial bioenergetics and oxygen consumption in pulmonary arterial endothelial cells after a $3 \mathrm{~h}$ incubation period (36). TRPV4 can also negatively regulate expression of peroxisome proliferatoractivated receptor $\gamma(\operatorname{PPAR} \gamma)$ coactivator $1 \alpha(\mathrm{PGC} 1 \alpha)$, mitochondrial uncoupling protein 1 (UCP1), and cellular respiration in adipocytes (103). PGC- $1 \alpha$ is a transcriptional coregulator of pPPAR $\gamma$, controlling the UCP1 promoter, which is involved in mitochondrial biogenesis and oxidative metabolism. 
PPAR $\gamma$ is an important transcription factor of M2 macrophages and is associated with fatty acid uptake and oxidation.

Pharmacological activation of TRPV4 also triggers secretion of pro-inflammatory lipid mediators including prostaglandins, suggesting a potential link between this ion channel and fatty acid biosynthesis $(14,43)$. Collectively, the metabolic profile of TRPV4-activated cells shares some similarities with the profile of the pro-inflammatory macrophage phenotype including high glycolysis, low OXPHOS activity and increased synthesis of pro-inflammatory lipids.

\section{INVESTIGATING PLEIOTROPIC ROLES OF TRPV4 USING A SYSTEMS BIOLOGY APPROACH}

This approach utilizes high-throughput omics platforms to interrogate complex biological systems. In contrast to most targeted studies outlined above, systems biology can comprehensively characterize molecular profiles at the level of the genome, transcriptome, proteome, peptidome, metabolome and lipidome in an unbiased manner (104-109). These approaches are well suited to the study of TRPV4 function in macrophages as these cells secrete mediators and their metabolic activity is highly regulated and linked to the inflammatory state.

\section{i) Metabolic Profiling in Mechanobiology and Immunology}

Metabolomic methods have revealed novel biological pathways and important metabolites in inflammatory responses and have identified signature metabolites associated with different macrophage phenotypes (110-112). This includes the distinct metabolomic profiles of central carbon metabolism between M1 and M2 macrophages, as outlined above.

There are relatively few studies that examine the role of TRPV4 at a metabolic level (11, 36-42, 102). Furthermore, these are limited to targeted pathways including cellular respiration, NO production, and bioactive lipids, such as prostaglandins (Table 1). For example, targeted studies of isolated mouse alveolar macrophages have shown that 4- $\alpha \mathrm{PDD}$ activates TRPV4 to promote $\mathrm{Ca}^{2+}$ influx and subsequent release of NO and superoxide (11). The combination of $\mathrm{NO}$ and superoxide can produce peroxynitrite, a strong oxidant involved in pathogen defense and inflammation $(113,114)$. Untargeted global profiling of TRPV4-induced macrophage phenotypes could help to address important questions of how and why TRPV4 can have both pro- and anti-inflammatory responses, and further understand the underlying mechanisms involved.

\section{ii) Profiling TRPV4-Mediated Lipid Synthesis and Metabolism}

Macrophages are an important source of bioactive lipid mediators which are important determinants of the magnitude and duration of inflammatory signaling. In the onset phase of acute inflammation, eicosanoid lipid mediators (leukotrienes and prostaglandins) are released to promote inflammation (115, 116). At the resolution phase, cells switch to production of specialized pro-resolving mediators, such as lipoxins, resolvins, protectins, and maresins to resolve inflammation $(115,116)$. The imbalance of pro-inflammatory and pro-resolving mediators results in chronic inflammation $(115,116)$. Although TRPV4 activity can affect lipid metabolism in macrophages, including prostaglandin E2 (PGE2) production (14), this process has not been examined in detail and remains poorly characterized. The release of prostaglandins at the early stages of acute inflammation is important for a protective response. However, excessive production can promote chronic inflammation (115, $117,118)$.

There is a clear need for more detailed investigation into how TRPV4 may influence lipid metabolism in the context of inflammatory disease. A comprehensive and unbiased lipidomics approach will provide mechanistic insight beyond that provided by current studies and significantly advance understanding of how TRPV4-mediated secretion of bioactive lipid mediators contributes to the initiation and resolution of inflammation.

\section{iii) Profiling the Protein Interactome}

TRPV4 can directly or indirectly interact with a broad range of proteins $(53,56,119)$. Mass spectrometry-based proteomics has become the core technology for large-scale investigation of protein-protein interactions with high confidence. Many purification methods have been developed to enable single protein complex characterization through to global interactome profiling (120). Commonly used workflows for purification of the target protein and its interactors include antibody-based affinity-purification mass spectrometry (APMS) (121), quantitative immunoprecipitation combined with knock-down (QUICK) (122), and proximity-ligation techniques such as BioID (123). The global interactome profiling requires biochemical techniques including fractionation by size-exclusion chromatography (SEC), ionexchange chromatography (IEX), or perturbation co-behavior approach. The pros and cons of each of these workflows are covered elsewhere (120). Comprehensive analysis of the proteinprotein interaction network will enable novel insight into the contribution of TRPV4 to cellular biology beyond what is possible with currently used methodology. Furthermore, this approach may facilitate identification of new avenues and targets to enable therapeutic modulation of TRPV4-dependent inflammatory signaling.

\section{CONCLUDING REMARKS}

This review provides an overview of how TRPV4 influences macrophage function in pathological conditions and highlights the dual roles that this channel has in promoting and preventing inflammation. There is little doubt that TRPV4 is important for maintaining homeostasis and immune responses. This includes: 1) responses to pathogens and changes in biophysical factors including mechanical stress and matrix stiffness, 2) mediating 
inflammatory responses (phagocytosis, cytokine secretion) and balancing pro- and anti-inflammatory cytokine secretion, and 3) facilitating cell-cell communication via secreted factors. However, the underlying mechanisms involved in each role are not fully understood. In addition, cytokines and bioactive lipids secreted by macrophages are essential mediators of the inflammatory response. The importance of TRPV4 for macrophage polarization and associated production of cytokines is well documented. In contrast, current understanding of how TRPV4 regulates synthesis of bioactive lipids, protein expression, and protein-protein interactions is limited. This suggests that a focus on this specific research area using more comprehensive analysis methods is required. Application of high-throughput omics approaches to definitively characterize the effects of TRPV4 modulation on macrophages may reveal novel functions and pathways important for understanding the precise involvement of TRPV4 in inflammatory and protective processes. Similar methods have been widely applied in the immunology field,

\section{REFERENCES}

1. Medzhitov R. Inflammation 2010: New Adventures of an Old Flame. Cell (2010) 140(6):771-6. doi: 10.1016/j.cell.2010.03.006

2. Reville K, Crean JK, Vivers S, Dransfield I, Godson C. Lipoxin A4 Redistributes Myosin IIA and Cdc42 in Macrophages: Implications for Phagocytosis of Apoptotic Leukocytes. J Immunol (2006) 176(3):1878-88. doi: 10.4049/jimmunol.176.3.1878

3. Serhan CN, Savill J. Resolution of Inflammation: The Beginning Programs the End. Nat Immunol (2005) 6(12):1191-7. doi: 10.1038/ni1276

4. McInnes IB, Schett G. Pathogenetic Insights From the Treatment of Rheumatoid Arthritis. Lancet (2017) 389(10086):2328-37. doi: 10.1016/ S0140-6736(17)31472-1

5. Nielsen OH, Ainsworth MA. Tumor Necrosis Factor Inhibitors for Inflammatory Bowel Disease. N Engl J Med (2013) 369(8):754-62. doi: 10.1056/NEJMct1209614

6. Barnes PJ. Targeting Cytokines to Treat Asthma and Chronic Obstructive Pulmonary Disease. Nat Rev Immunol (2018) 18(7):454-66. doi: 10.1038/ s41577-018-0006-6

7. Wolf D, Ley K. Immunity and Inflammation in Atherosclerosis. Circ Res (2019) 124(2):315-27. doi: 10.1161/CIRCRESAHA.118.313591

8. Veiseh O, Vegas AJ. Domesticating the Foreign Body Response: Recent Advances and Applications. Adv Drug Deliv Rev (2019) 144:148-61. doi: 10.1016/j.addr.2019.08.010

9. Jun JI, Lau LF. Resolution of Organ Fibrosis. J Clin Invest (2018) 128(1):97107. doi: 10.1172/JCI93563

10. Santoni G, Morelli MB, Amantini C, Santoni M, Nabissi M, Marinelli O, et al. "Immuno-Transient Receptor Potential Ion Channels": The Role in Monocyte- and Macrophage-Mediated Inflammatory Responses. Front Immunol (2018) 9:1273. doi: 10.3389/fimmu.2018.01273

11. Hamanaka K, Jian MY, Townsley MI, King JA, Liedtke W, Weber DS, et al. TRPV4 Channels Augment Macrophage Activation and Ventilator-Induced Lung Injury. Am J Physiol Lung Cell Mol Physiol (2010) 299(3):L353-62. doi: 10.1152/ajplung.00315.2009

12. Scheraga RG, Abraham S, Grove LM, Southern BD, Crish JF, Perelas A, et al. TRPV4 Protects the Lung From Bacterial Pneumonia via MAPK Molecular Pathway Switching. J Immunol (2020) 204(5):1310-21. doi: 10.4049/ jimmunol.1901033

13. Scheraga RG, Abraham S, Niese KA, Southern BD, Grove LM, Hite RD, et al. TRPV4 Mechanosensitive Ion Channel Regulates LipopolysaccharideStimulated Macrophage Phagocytosis. J Immunol (2016) 196(1):428-36. doi: 10.4049/jimmunol.1501688 which has helped to further differentiate pro- and antiinflammatory macrophage phenotypes $(107,124,125)$. This information is critical for understanding how TRPV4 can influence both inflammatory and resolving processes and will contribute to future therapeutic targeting of TRPV4 in inflammatory diseases.

\section{AUTHOR CONTRIBUTIONS}

T-NN, GS, NV, and DP reviewed the literature and wrote the manuscript. All authors contributed to the article and approved the submitted version.

\section{FUNDING}

ARC Centre of Excellence in Convergent Bio-Nano Science and Technology (CE14100036).

14. Luo J, Qian A, Oetjen LK, Yu W, Yang P, Feng J, et al. TRPV4 Channe Signaling in Macrophages Promotes Gastrointestinal Motility via Direct Effects on Smooth Muscle Cells. Immunity (2018) 49(1):107-19.e4 doi: 10.1016/j.immuni.2018.04.021

15. Yin J, Michalick L, Tang C, Tabuchi A, Goldenberg N, Dan Q, et al. Role of Transient Receptor Potential Vanilloid 4 in Neutrophil Activation and Acute Lung Injury. Am J Respir Cell Mol Biol (2016) 54(3):370-83. doi: 10.1165/ rcmb.2014-0225OC

16. Naert R, Lopez-Requena A, Voets T, Talavera K, Alpizar YA. Expression and Functional Role of TRPV4 in Bone Marrow-Derived CD11c(+) Cells. Int J Mol Sci (2019) 20(14):3378. doi: 10.3390/ijms20143378

17. Dutta B, Goswami R, Rahaman SO. TRPV4 Plays a Role in Matrix StiffnessInduced Macrophage Polarization. Front Immunol (2020) 11:570195. doi: 10.3389/fimmu.2020.570195

18. Dutta B, Arya RK, Goswami R, Alharbi MO, Sharma S, Rahaman SO. Role of Macrophage TRPV4 in Inflammation. Lab Invest (2020) 100(2):178-85. doi: 10.1038/s41374-019-0334-6

19. Luo J, Feng J, Yu G, Yang P, Mack MR, Du J, et al. Transient Receptor Potential Vanilloid 4-Expressing Macrophages and Keratinocytes Contribute Differentially to Allergic and Nonallergic Chronic Itch. J Allergy Clin Immunol (2018) 141(2):608-19.e7. doi: 10.1016/j.jaci.2017.05.051

20. Seth RK, Das S, Dattaroy D, Chandrashekaran V, Alhasson F, Michelotti G, et al. TRPV4 Activation of Endothelial Nitric Oxide Synthase Resists Nonalcoholic Fatty Liver Disease by Blocking CYP2E1-Mediated Redox Toxicity. Free Radic Biol Med (2017) 102:260-73. doi: 10.1016/ j.freeradbiomed.2016.11.047

21. Liu M, Liu X, Wang L, Wang Y, Dong F, Wu J, et al. TRPV4 Inhibition Improved Myelination and Reduced Glia Reactivity and Inflammation in a Cuprizone-Induced Mouse Model of Demyelination. Front Cell Neurosci (2018) 12:392. doi: 10.3389/fncel.2018.00392

22. Naik SK, Pattanaik K, Eich J, Sparr V, Hauptmann M, Kalsdorf B, et al. Differential Roles of the Calcium Ion Channel TRPV4 in Host Responses to Mycobacterium Tuberculosis Early and Late in Infection. iScience (2020) 23 (6):101206. doi: 10.1016/j.isci.2020.101206

23. Strotmann R, Harteneck C, Nunnenmacher K, Schultz G, Plant TD OTRPC4, a Nonselective Cation Channel That Confers Sensitivity to Extracellular Osmolarity. Nat Cell Biol (2000) 2(10):695-702. doi: 10.1038/ 35036318

24. Liedtke W, Choe Y, Marti-Renom MA, Bell AM, Denis CS, Sali A, et al. Vanilloid Receptor-Related Osmotically Activated Channel (VR-OAC), a Candidate Vertebrate Osmoreceptor. Cell (2000) 103(3):525-35. doi: 10.1016/s0092-8674(00)00143-4 
25. Loukin S, Zhou X, Su Z, Saimi Y, Kung C. Wild-Type and BrachyolmiaCausing Mutant TRPV4 Channels Respond Directly to Stretch Force. J Biol Chem (2010) 285(35):27176-81. doi: 10.1074/jbc.M110.143370

26. Ryskamp DA, Frye AM, Phuong TT, Yarishkin O, Jo AO, Xu Y, et al. TRPV4 Regulates Calcium Homeostasis, Cytoskeletal Remodeling, Conventional Outflow and Intraocular Pressure in the Mammalian Eye. Sci Rep (2016) 6:30583. doi: $10.1038 / \mathrm{srep} 30583$

27. Servin-Vences MR, Moroni M, Lewin GR, Poole K. Direct Measurement of TRPV4 and PIEZO1 Activity Reveals Multiple Mechanotransduction Pathways in Chondrocytes. Elife (2017) 6. doi: $10.7554 /$ eLife. 21074

28. Sianati S, Schroeter L, Richardson J, Tay A, Lamande SR, Poole K. Modulating the Mechanical Activation of TRPV4 at the Cell-Substrate Interface. Front Bioeng Biotechnol (2020) 8:608951. doi: 10.3389/ fbioe.2020.608951

29. Guler AD, Lee H, Iida T, Shimizu I, Tominaga M, Caterina M. Heat-Evoked Activation of the Ion Channel, TRPV4. J Neurosci (2002) 22(15):6408-14. doi: 10.1523/JNEUROSCI.22-15-06408.2002

30. Chung MK, Lee H, Caterina MJ. Warm Temperatures Activate TRPV4 in Mouse 308 Keratinocytes. J Biol Chem (2003) 278(34):32037-46. doi: 10.1074/jbc.M303251200

31. Everaerts W, Nilius B, Owsianik G. The Vanilloid Transient Receptor Potential Channel TRPV4: From Structure to Disease. Prog Biophys Mol Biol (2010) 103(1):2-17. doi: 10.1016/j.pbiomolbio.2009.10.002

32. Vriens J, Owsianik G, Fisslthaler B, Suzuki M, Janssens A, Voets T, et al. Modulation of the Ca2 Permeable Cation Channel TRPV4 by Cytochrome P450 Epoxygenases in Vascular Endothelium. Circ Res (2005) 97(9):908-15. doi: 10.1161/01.RES.0000187474.47805.30

33. Watanabe H, Vriens J, Prenen J, Droogmans G, Voets T, Nilius B. Anandamide and Arachidonic Acid Use Epoxyeicosatrienoic Acids to Activate TRPV4 Channels. Nature (2003) 424(6947):434-8. doi: 10.1038/ nature 01807

34. Veldhuis NA, Poole DP, Grace M, McIntyre P, Bunnett NW. The G ProteinCoupled Receptor-Transient Receptor Potential Channel Axis: Molecular Insights for Targeting Disorders of Sensation and Inflammation. Pharmacol Rev (2015) 67(1):36-73. doi: 10.1124/pr.114.009555

35. D'Aldebert E, Cenac N, Rousset P, Martin L, Rolland C, Chapman K, et al. Transient Receptor Potential Vanilloid 4 Activated Inflammatory Signals by Intestinal Epithelial Cells and Colitis in Mice. Gastroenterology (2011) 140 (1):275-85. doi: 10.1053/j.gastro.2010.09.045

36. Lu Q, Zemskov EA, Sun X, Wang H, Yegambaram M, Wu X, et al. Activation of the Mechanosensitive $\mathrm{Ca}(2+)$ Channel TRPV4 Induces Endothelial Barrier Permeability via the Disruption of Mitochondrial Bioenergetics. Redox Biol (2021) 38:101785. doi: 10.1016/j.redox. 2020.101785

37. Mihara H, Boudaka A, Sugiyama T, Moriyama Y, Tominaga M. Transient Receptor Potential Vanilloid 4 (TRPV4)-Dependent Calcium Influx and ATP Release in Mouse Oesophageal Keratinocytes. J Physiol (2011) 589(Pt 14):3471-82. doi: 10.1113/jphysiol.2011.207829

38. Baxter M, Eltom S, Dekkak B, Yew-Booth L, Dubuis ED, Maher SA, et al. Role of Transient Receptor Potential and Pannexin Channels in Cigarette Smoke-Triggered ATP Release in the Lung. Thorax (2014) 69(12):1080-9. doi: 10.1136/thoraxjnl-2014-205467

39. Ueda T, Shikano M, Kamiya T, Joh T, Ugawa S. The TRPV4 Channel is a Novel Regulator of Intracellular Ca2+ in Human Esophageal Epithelial Cells. Am J Physiol Gastrointest Liver Physiol (2011) 301(1):G138-47. doi: 10.1152/ ajpgi.00511.2010

40. Li Q, Kresge C, Boggs K, Scott J, Feranchak A. Mechanosensor Transient Receptor Potential Vanilloid Member 4 (TRPV4) Regulates Mouse Cholangiocyte Secretion and Bile Formation. Am J Physiol Gastrointest Liver Physiol (2020) 318(2):G277-G87. doi: 10.1152/ajpgi.00176.2019

41. Mochizuki T, Sokabe T, Araki I, Fujishita K, Shibasaki K, Uchida K, et al. The TRPV4 Cation Channel Mediates Stretch-Evoked Ca2+ Influx and ATP Release in Primary Urothelial Cell Cultures. J Biol Chem (2009) 284 (32):21257-64. doi: 10.1074/jbc.M109.020206

42. Shibasaki K, Ikenaka K, Tamalu F, Tominaga M, Ishizaki Y. A Novel Subtype of Astrocytes Expressing TRPV4 (Transient Receptor Potential Vanilloid 4) Regulates Neuronal Excitability via Release of
Gliotransmitters. J Biol Chem (2014) 289(21):14470-80. doi: 10.1074/ jbc.M114.557132

43. Zhang P, Sun C, Li H, Tang C, Kan H, Yang Z, et al. TRPV4 (Transient Receptor Potential Vanilloid 4) Mediates Endothelium-Dependent Contractions in the Aortas of Hypertensive Mice. Hypertension (2018) 71 (1):134-42. doi: 10.1161/HYPERTENSIONAHA.117.09767

44. Pairet N, Mang S, Fois G, Keck M, Kuhnbach M, Gindele J, et al. TRPV4 Inhibition Attenuates Stretch-Induced Inflammatory Cellular Responses and Lung Barrier Dysfunction During Mechanical Ventilation. PloS One (2018) 13(4):e0196055. doi: 10.1371/journal.pone.0196055

45. Dalsgaard T, Sonkusare SK, Teuscher C, Poynter ME, Nelson MT. Pharmacological Inhibitors of TRPV4 Channels Reduce Cytokine Production, Restore Endothelial Function and Increase Survival in Septic Mice. Sci Rep (2016) 6:33841. doi: 10.1038/srep33841

46. Matsumoto H, Sugio S, Seghers F, Krizaj D, Akiyama H, Ishizaki Y, et al. Retinal Detachment-Induced Muller Glial Cell Swelling Activates TRPV4 Ion Channels and Triggers Photoreceptor Death at Body Temperature. J Neurosci (2018) 38(41):8745-58. doi: 10.1523/JNEUROSCI.0897-18.2018

47. Boudaka A, Saito CT, Tominaga M. Deletion of TRPV4 Enhances In Vitro Wound Healing of Murine Esophageal Keratinocytes. Sci Rep (2020) 10 (1):11349. doi: 10.1038/s41598-020-68269-8

48. Mihara H, Suzuki N, Boudaka AA, Muhammad JS, Tominaga M, Tabuchi Y, et al. Transient Receptor Potential Vanilloid 4-Dependent Calcium Influx and ATP Release in Mouse and Rat Gastric Epithelia. World J Gastroenterol (2016) 22(24):5512-9. doi: 10.3748/wjg.v22.i24.5512

49. Sun L, Yao K, Zhang H, Chen W. Activation of the ATP-P2X Pathway by TRPV4 in Acute Ocular Hypertension. Int J Ophthalmol (2020) 13 (11):1697-704. doi: 10.18240/ijo.2020.11.03

50. Jay SM, Skokos E, Laiwalla F, Krady MM, Kyriakides TR. Foreign Body Giant Cell Formation is Preceded by Lamellipodia Formation and can be Attenuated by Inhibition of Rac1 Activation. Am J Pathol (2007) 171 (2):632-40. doi: 10.2353/ajpath.2007.061213

51. Ou-Yang Q, Li B, Xu M, Liang H. TRPV4 Promotes the Migration and Invasion of Glioma Cells via AKT/Rac1 Signaling. Biochem Biophys Res Commun (2018) 503(2):876-81. doi: 10.1016/j.bbrc.2018.06.090

52. Arya RK, Goswami R, Rahaman SO. Mechanotransduction via a TRPV4Rac1 Signaling Axis Plays a Role in Multinucleated Giant Cell Formation. J Biol Chem (2021) 296:100129. doi: 10.1074/jbc.RA120.014597

53. White JP, Cibelli M, Urban L, Nilius B, McGeown JG, Nagy I. TRPV4: Molecular Conductor of a Diverse Orchestra. Physiol Rev (2016) 96(3):91173. doi: $10.1152 /$ physrev.00016.2015

54. Soya M, Sato M, Sobhan U, Tsumura M, Ichinohe T, Tazaki M, et al. Plasma Membrane Stretch Activates Transient Receptor Potential Vanilloid and Ankyrin Channels in Merkel Cells From Hamster Buccal Mucosa. Cell Calcium (2014) 55(4):208-18. doi: 10.1016/j.ceca.2014.02.015

55. Vriens J, Watanabe H, Janssens A, Droogmans G, Voets T, Nilius B. Cell Swelling, Heat, and Chemical Agonists Use Distinct Pathways for the Activation of the Cation Channel TRPV4. Proc Natl Acad Sci USA (2004) 101(1):396-401. doi: 10.1073/pnas.0303329101

56. Poole DP, Amadesi S, Veldhuis NA, Abogadie FC, Lieu T, Darby W, et al. Protease-Activated Receptor 2 (PAR2) Protein and Transient Receptor Potential Vanilloid 4 (TRPV4) Protein Coupling is Required for Sustained Inflammatory Signaling. J Biol Chem (2013) 288(8):5790-802. doi: 10.1074/ jbc.M112.438184

57. Kechagia JZ, Ivaska J, Roca-Cusachs P. Integrins as Biomechanical Sensors of the Microenvironment. Nat Rev Mol Cell Biol (2019) 20(8):457-73. doi: 10.1038/s41580-019-0134-2

58. Matthews BD, Thodeti CK, Tytell JD, Mammoto A, Overby DR, Ingber DE. Ultra-Rapid Activation of TRPV4 Ion Channels by Mechanical Forces Applied to Cell Surface Betal Integrins. Integr Biol (Camb) (2010) 2 (9):435-42. doi: 10.1039/c0ib00034e

59. Potla R, Hirano-Kobayashi M, Wu H, Chen H, Mammoto A, Matthews BD, et al. Molecular Mapping of Transmembrane Mechanotransduction Through the Beta1 Integrin-CD98hc-TRPV4 Axis. J Cell Sci (2020) 133 (20). doi: $10.1242 /$ jcs. 248823

60. Swain SM, Liddle RA. Piezo1 Acts Upstream of TRPV4 to Induce Pathological Changes in Endothelial Cells Due to Shear Stress. J Biol Chem (2021) 296:100171. doi: 10.1074/jbc.RA120.015059 
61. Swain SM, Romac JM, Shahid RA, Pandol SJ, Liedtke W, Vigna SR, et al. TRPV4 Channel Opening Mediates Pressure-Induced Pancreatitis Initiated by Piezo1 Activation. J Clin Invest (2020) 130(5):2527-41. doi: 10.1172/ JCI134111

62. Li M, Fang XZ, Zheng YF, Xie YB, Ma XD, Liu XT, et al. Transient Receptor Potential Vanilloid 4 is a Critical Mediator in LPS Mediated Inflammation by Mediating Calcineurin/NFATc3 Signaling. Biochem Biophys Res Commun (2019) 513(4):1005-12. doi: 10.1016/j.bbrc.2019.04.020

63. Rayees S, Joshi JC, Tauseef M, Anwar M, Baweja S, Rochford I, et al. PAR2Mediated cAMP Generation Suppresses TRPV4-Dependent Ca(2+) Signaling in Alveolar Macrophages to Resolve TLR4-Induced Inflammation. Cell Rep (2019) 27(3):793-805.e4. doi: 10.1016/j.celrep.2019.03.053

64. Fernandez-Fernandez JM, Nobles M, Currid A, Vazquez E, Valverde MA. Maxi K+ Channel Mediates Regulatory Volume Decrease Response in a Human Bronchial Epithelial Cell Line. Am J Physiol Cell Physiol (2002) 283 (6):C1705-14. doi: 10.1152/ajpcell.00245.2002

65. Jia Y, Wang X, Varty L, Rizzo CA, Yang R, Correll CC, et al. Functional TRPV4 Channels are Expressed in Human Airway Smooth Muscle Cells. Am J Physiol Lung Cell Mol Physiol (2004) 287(2):L272-8. doi: 10.1152/ ajplung.00393.2003

66. Wissenbach U, Bodding M, Freichel M, Flockerzi V. Trp12, a Novel Trp Related Protein From Kidney. FEBS Lett (2000) 485(2-3):127-34. doi: 10.1016/S0014-5793(00)02212-2

67. Delany NS, Hurle M, Facer P, Alnadaf T, Plumpton C, Kinghorn I, et al. Identification and Characterization of a Novel Human Vanilloid ReceptorLike Protein, VRL-2. Physiol Genomics (2001) 4(3):165-74. doi: 10.1152/ physiolgenomics.2001.4.3.165

68. Birder L, Kullmann FA, Lee H, Barrick S, de Groat W, Kanai A, et al. Activation of Urothelial Transient Receptor Potential Vanilloid 4 by 4alphaPhorbol 12,13-Didecanoate Contributes to Altered Bladder Reflexes in the Rat. J Pharmacol Exp Ther (2007) 323(1):227-35. doi: 10.1124/ jpet.107.125435

69. Gevaert T, Vriens J, Segal A, Everaerts W, Roskams T, Talavera K, et al. Deletion of the Transient Receptor Potential Cation Channel TRPV4 Impairs Murine Bladder Voiding. J Clin Invest (2007) 117(11):3453-62. doi: $10.1172 / \mathrm{JCI} 31766$

70. Shen J, Harada N, Kubo N, Liu B, Mizuno A, Suzuki M, et al. Functional Expression of Transient Receptor Potential Vanilloid 4 in the Mouse Cochlea. Neuroreport (2006) 17(2):135-9. doi: 10.1097/01.wnr.0000199459.16789.75

71. Groot-Kormelink PJ, Fawcett L, Wright PD, Gosling M, Kent TC. Quantitative GPCR and Ion Channel Transcriptomics in Primary Alveolar Macrophages and Macrophage Surrogates. BMC Immunol (2012) 13:57. doi: $10.1186 / 1471-2172-13-57$

72. Rajasekhar P, Poole DP, Veldhuis NA. Role of Nonneuronal TRPV4 Signaling in Inflammatory Processes. Adv Pharmacol (2017) 79:117-39. doi: 10.1016/bs.apha.2017.03.002

73. Filosa JA, Yao X, Rath G. TRPV4 and the Regulation of Vascular Tone. J Cardiovasc Pharmacol (2013) 61(2):113-9. doi: 10.1097/FJC. 0b013e318279ba42

74. Toft-Bertelsen TL, Krizaj D, MacAulay N. When Size Matters: Transient Receptor Potential Vanilloid 4 Channel as a Volume-Sensor Rather Than an Osmo-Sensor. J Physiol (2017) 595(11):3287-302. doi: 10.1113/ JP274135

75. Watanabe H, Davis JB, Smart D, Jerman JC, Smith GD, Hayes P, et al. Activation of TRPV4 Channels (hVRL-2/Mtrp12) by Phorbol Derivatives. J Biol Chem (2002) 277(16):13569-77. doi: 10.1074/jbc. M200062200

76. Hartmannsgruber V, Heyken WT, Kacik M, Kaistha A, Grgic I, Harteneck C, et al. Arterial Response to Shear Stress Critically Depends on Endothelial TRPV4 Expression. PloS One (2007) 2(9):e827. doi: 10.1371/journal. pone. 0000827

77. Nilius B, Voets T. The Puzzle of TRPV4 Channelopathies. EMBO Rep (2013) 14(2):152-63. doi: 10.1038/embor.2012.219

78. Rahaman SO, Grove LM, Paruchuri S, Southern BD, Abraham S, Niese KA, et al. TRPV4 Mediates Myofibroblast Differentiation and Pulmonary Fibrosis in Mice. J Clin Invest (2014) 124(12):5225-38. doi: 10.1172/ JCI75331
79. Lawhorn BG, Brnardic EJ, Behm DJ. TRPV4 Antagonists: A Patent Review (2015-2020). Expert Opin Ther Pat (2021) 31:773-84. doi: 10.1080/ 13543776.2021 .1903432

80. Atobe M. Activation of Transient Receptor Potential Vanilloid (TRPV) 4 as a Therapeutic Strategy in Osteoarthritis. Curr Top Med Chem (2019) 19 (24):2254-67. doi: 10.2174/1568026619666191010162850

81. Atobe M, Nagami T, Muramatsu S, Ohno T, Kitagawa M, Suzuki H, et al. Discovery of Novel Transient Receptor Potential Vanilloid 4 (TRPV4) Agonists as Regulators of Chondrogenic Differentiation: Identification of Quinazolin-4(3 H)-Ones and in Vivo Studies on a Surgically Induced Rat Model of Osteoarthritis. J Med Chem (2019) 62(3):1468-83. doi: 10.1021/ acs.jmedchem. $8 \mathrm{~b} 01615$

82. Xu S, Liu B, Yin M, Koroleva M, Mastrangelo M, Ture S, et al. A Novel TRPV4-Specific Agonist Inhibits Monocyte Adhesion and Atherosclerosis. Oncotarget (2016) 7(25):37622-35. doi: 10.18632/oncotarget.9376

83. Thoppil RJ, Adapala RK, Cappelli HC, Kondeti V, Dudley AC, Gary Meszaros J, et al. TRPV4 Channel Activation Selectively Inhibits Tumor Endothelial Cell Proliferation. Sci Rep (2015) 5:14257. doi: 10.1038/ srep14257

84. Adapala RK, Thoppil RJ, Ghosh K, Cappelli HC, Dudley AC, Paruchuri S, et al. Activation of Mechanosensitive Ion Channel TRPV4 Normalizes Tumor Vasculature and Improves Cancer Therapy. Oncogene (2016) 35 (3):314-22. doi: 10.1038/onc.2015.83

85. Peters AA, Jamaludin SYN, Yapa K, Chalmers S, Wiegmans AP, Lim HF, et al. Oncosis and Apoptosis Induction by Activation of an Overexpressed Ion Channel in Breast Cancer Cells. Oncogene (2017) 36(46):6490-500. doi: 10.1038/onc.2017.234

86. Kuebler WM, Jordt SE, Liedtke WB. Urgent Reconsideration of Lung Edema as a Preventable Outcome in COVID-19: Inhibition of TRPV4 Represents a Promising and Feasible Approach. Am J Physiol Lung Cell Mol Physiol (2020) 318(6):L1239-43. doi: 10.1152/ajplung.00161.2020

87. Goyal N, Skrdla P, Schroyer R, Kumar S, Fernando D, Oughton A, et al. Clinical Pharmacokinetics, Safety, and Tolerability of a Novel, First-In-Class TRPV4 Ion Channel Inhibitor, GSK2798745, in Healthy and Heart Failure Subjects. Am J Cardiovasc Drugs (2019) 19(3):335-42. doi: 10.1007/s40256018-00320-6

88. Stewart GM, Johnson BD, Sprecher DL, Reddy YNV, Obokata M, Goldsmith S, et al. Targeting Pulmonary Capillary Permeability to Reduce Lung Congestion in Heart Failure: A Randomized, Controlled Pilot Trial. Eur J Heart Fail (2020) 22(9):1641-5. doi: 10.1002/ejhf.1809

89. McNulty AL, Leddy HA, Liedtke W, Guilak F. TRPV4 as a Therapeutic Target for Joint Diseases. Naunyn Schmiedebergs Arch Pharmacol (2015) 388 (4):437-50. doi: 10.1007/s00210-014-1078-x

90. Palsson-McDermott EM, O'Neill LAJ. Targeting Immunometabolism as an Anti-Inflammatory Strategy. Cell Res (2020) 30(4):300-14. doi: 10.1038/ s41422-020-0291-z

91. Spiller KL, Koh TJ. Macrophage-Based Therapeutic Strategies in Regenerative Medicine. Adv Drug Deliv Rev (2017) 122:74-83. doi: 10.1016/ j.addr.2017.05.010

92. O'Neill LA, Pearce EJ. Immunometabolism Governs Dendritic Cell and Macrophage Function. J Exp Med (2016) 213(1):15-23. doi: 10.1084/ jem. 20151570

93. Viola A, Munari F, Sanchez-Rodriguez R, Scolaro T, Castegna A. The Metabolic Signature of Macrophage Responses. Front Immunol (2019) 10:1462. doi: 10.3389/fimmu.2019.01462

94. Lee WH, Choong LY, Jin TH, Mon NN, Chong S, Liew CS, et al. TRPV4 Plays a Role in Breast Cancer Cell Migration via $\mathrm{Ca}(2+)$-Dependent Activation of AKT and Downregulation of E-Cadherin Cell Cortex Protein. Oncogenesis (2017) 6(5):e338. doi: 10.1038/oncsis.2017.39

95. Ballotta V, Driessen-Mol A, Bouten CV, Baaijens FP. Strain-Dependent Modulation of Macrophage Polarization Within Scaffolds. Biomaterials (2014) 35(18):4919-28. doi: 10.1016/j.biomaterials.2014.03.002

96. Wehner S, Buchholz BM, Schuchtrup S, Rocke A, Schaefer N, Lysson M, et al. Mechanical Strain and TLR4 Synergistically Induce Cell-Specific Inflammatory Gene Expression in Intestinal Smooth Muscle Cells and Peritoneal Macrophages. Am J Physiol Gastrointest Liver Physiol (2010) 299(5):G1187-97. doi: 10.1152/ajpgi.00452.2009 
97. Previtera ML, Sengupta A. Substrate Stiffness Regulates Proinflammatory Mediator Production Through TLR4 Activity in Macrophages. PloS One (2015) 10(12):e0145813. doi: 10.1371/journal.pone.0145813

98. Chen M, Zhang Y, Zhou P, Liu X, Zhao H, Zhou X, et al. Substrate Stiffness Modulates Bone Marrow-Derived Macrophage Polarization Through NFkappaB Signaling Pathway. Bioact Mater (2020) 5(4):880-90. doi: 10.1016/ j.bioactmat.2020.05.004

99. Pietrogrande G, Mabotuwana N, Zhao Z, Abdolhoseini M, Johnson SJ, Nilsson M, et al. Chronic Stress Induced Disturbances in Laminin: A Significant Contributor to Modulating Microglial Pro-Inflammatory Tone? Brain Behav Immun (2018) 68:23-33. doi: 10.1016/j.bbi.2017.09.012

100. Sridharan R, Cavanagh B, Cameron AR, Kelly DJ, O'Brien FJ. Material Stiffness Influences the Polarization State, Function and Migration Mode of Macrophages. Acta Biomater (2019) 89:47-59. doi: 10.1016/j.actbio.2019.02.048

101. Blakney AK, Swartzlander MD, Bryant SJ. The Effects of Substrate Stiffness on the In Vitro Activation of Macrophages and In Vivo Host Response to Poly(Ethylene Glycol)-Based Hydrogels. J BioMed Mater Res A (2012) 100 (6):1375-86. doi: 10.1002/jbm.a.34104

102. Alpizar YA, Boonen B, Sanchez A, Jung C, Lopez-Requena A, Naert R, et al. TRPV4 Activation Triggers Protective Responses to Bacterial Lipopolysaccharides in Airway Epithelial Cells. Nat Commun (2017) 8 (1):1059. doi: 10.1038/s41467-017-01201-3

103. Ye L, Kleiner S, Wu J, Sah R, Gupta RK, Banks AS, et al. TRPV4 is a Regulator of Adipose Oxidative Metabolism, Inflammation, and Energy Homeostasis. Cell (2012) 151(1):96-110. doi: 10.1016/j.cell.2012.08.034

104. Lee WC, Reuben A, Hu X, McGranahan N, Chen R, Jalali A, et al. Multiomics Profiling of Primary Lung Cancers and Distant Metastases Reveals Immunosuppression as a Common Characteristic of Tumor Cells With Metastatic Plasticity. Genome Biol (2020) 21(1):271. doi: 10.1186/ s13059-020-02175-0

105. Wilson JL, Nagele T, Linke M, Demel F, Fritsch SD, Mayr HK, et al. Inverse Data-Driven Modeling and Multiomics Analysis Reveals Phgdh as a Metabolic Checkpoint of Macrophage Polarization and Proliferation. Cell Rep (2020) 30(5):1542-52.e7. doi: 10.1016/j.celrep.2020.01.011

106. Yang X. Multitissue Multiomics Systems Biology to Dissect Complex Diseases. Trends Mol Med (2020) 26(8):718-28. doi: 10.1016/j.molmed.2020.04.006

107. Hsieh WY, Zhou QD, York AG, Williams KJ, Scumpia PO, Kronenberger $\mathrm{EB}$, et al. Toll-Like Receptors Induce Signal-Specific Reprogramming of the Macrophage Lipidome. Cell Metab (2020) 32(1):128-43.e5. doi: 10.1016/ j.cmet.2020.05.003

108. Lagerborg KA, Watrous JD, Cheng S, Jain M. High-Throughput Measure of Bioactive Lipids Using Non-Targeted Mass Spectrometry. Methods Mol Biol (2019) 1862:17-35. doi: 10.1007/978-1-4939-8769-6_2

109. Masoodi M, Eiden M, Koulman A, Spaner D, Volmer DA. Comprehensive Lipidomics Analysis of Bioactive Lipids in Complex Regulatory Networks. Anal Chem (2010) 82(19):8176-85. doi: 10.1021/ac1015563

110. Tannahill GM, Curtis AM, Adamik J, Palsson-McDermott EM, McGettrick AF, Goel G, et al. Succinate is an Inflammatory Signal That Induces IL-1beta Through HIF-1alpha. Nature (2013) 496(7444):238-42. doi: 10.1038/nature11986

111. O'Neill LAJ, Artyomov MN. Itaconate: The Poster Child of Metabolic Reprogramming in Macrophage Function. Nat Rev Immunol (2019) 19 (5):273-81. doi: 10.1038/s41577-019-0128-5

112. De Souza DP, Achuthan A, Lee MK, Binger KJ, Lee MC, Davidson S, et al. Autocrine IFN-I Inhibits Isocitrate Dehydrogenase in the TCA Cycle of LPSStimulated Macrophages. J Clin Invest (2019) 129(10):4239-44. doi: 10.1172/ JCI127597
113. Pacher P, Beckman JS, Liaudet L. Nitric Oxide and Peroxynitrite in Health and Disease. Physiol Rev (2007) 87(1):315-424. doi: 10.1152/physrev.00029.2006

114. Salvemini D, Doyle TM, Cuzzocrea S. Superoxide, Peroxynitrite and Oxidative/Nitrative Stress in Inflammation. Biochem Soc Trans (2006) 34 (Pt 5):965-70. doi: 10.1042/BST0340965

115. Buckley CD, Gilroy DW, Serhan CN. Proresolving Lipid Mediators and Mechanisms in the Resolution of Acute Inflammation. Immunity (2014) 40 (3):315-27. doi: 10.1016/j.immuni.2014.02.009

116. Serhan CN, Chiang N, Dalli J, Levy BD. Lipid Mediators in the Resolution of Inflammation. Cold Spring Harb Perspect Biol (2014) 7(2):a016311. doi: 10.1101/cshperspect.a016311

117. Serhan CN. Pro-Resolving Lipid Mediators are Leads for Resolution Physiology. Nature (2014) 510(7503):92-101. doi: 10.1038/nature13479

118. Flower RJ. Prostaglandins, Bioassay and Inflammation. Br J Pharmacol (2006) 147 Suppl 1:S182-92. doi: 10.1038/sj.bjp.0706506

119. Peng S, Grace MS, Gondin AB, Retamal JS, Dill L, Darby W, et al. The Transient Receptor Potential Vanilloid 4 (TRPV4) Ion Channel Mediates Protease Activated Receptor 1 (PAR1)-Induced Vascular Hyperpermeability. Lab Invest (2020) 100(8):1057-67. doi: 10.1038/s41374-020-0430-7

120. Smits AH, Vermeulen M. Characterizing Protein-Protein Interactions Using Mass Spectrometry: Challenges and Opportunities. Trends Biotechnol (2016) 34(10):825-34. doi: 10.1016/j.tibtech.2016.02.014

121. Morris JH, Knudsen GM, Verschueren E, Johnson JR, Cimermancic P, Greninger AL, et al. Affinity Purification-Mass Spectrometry and Network Analysis to Understand Protein-Protein Interactions. Nat Protoc (2014) 9 (11):2539-54. doi: 10.1038/nprot.2014.164

122. Ge F, Li WL, Bi LJ, Tao SC, Zhang ZP, Zhang XE. Identification of Novel 143-3zeta Interacting Proteins by Quantitative Immunoprecipitation Combined With Knockdown (QUICK). J Proteome Res (2010) 9(11):584858. doi: $10.1021 / \mathrm{pr} 100616 \mathrm{~g}$

123. Ummethum H, Hamperl S. Proximity Labeling Techniques to Study Chromatin. Front Genet (2020) 11:450. doi: 10.3389/fgene.2020.00450

124. Yang W, Zhao X, Tao Y, Wu Y, He F, Tang L. Proteomic Analysis Reveals a Protective Role of Specific Macrophage Subsets in Liver Repair. Sci Rep (2019) 9(1):2953. doi: 10.1038/s41598-019-39007-6

125. Court M, Petre G, Atifi ME, Millet A. Proteomic Signature Reveals Modulation of Human Macrophage Polarization and Functions Under Differing Environmental Oxygen Conditions. Mol Cell Proteomics (2017) 16(12):2153-68. doi: 10.1074/mcp.RA117.000082

Conflict of Interest: The authors declare that the research was conducted in the absence of any commercial or financial relationships that could be construed as a potential conflict of interest.

Publisher's Note: All claims expressed in this article are solely those of the authors and do not necessarily represent those of their affiliated organizations, or those of the publisher, the editors and the reviewers. Any product that may be evaluated in this article, or claim that may be made by its manufacturer, is not guaranteed or endorsed by the publisher.

Copyright (c) 2022 Nguyen, Siddiqui, Veldhuis and Poole. This is an open-access article distributed under the terms of the Creative Commons Attribution License (CC BY). The use, distribution or reproduction in other forums is permitted, provided the original author(s) and the copyright owner(s) are credited and that the original publication in this journal is cited, in accordance with accepted academic practice. No use, distribution or reproduction is permitted which does not comply with these terms. 